\title{
Measuring Parameters of Large-Aperture Crystals used for Generating Optical Harmonics
}

\author{
98-ERD-066 \\ Nonrefereed Report
}

R. E. English, Jr., R. L. Hibbard, R. B. Michie, P. J. Wegner, J. M. Auerbach, M. A. Norton, M. D. Summers, and S.A. Perfect

February 23, 1999

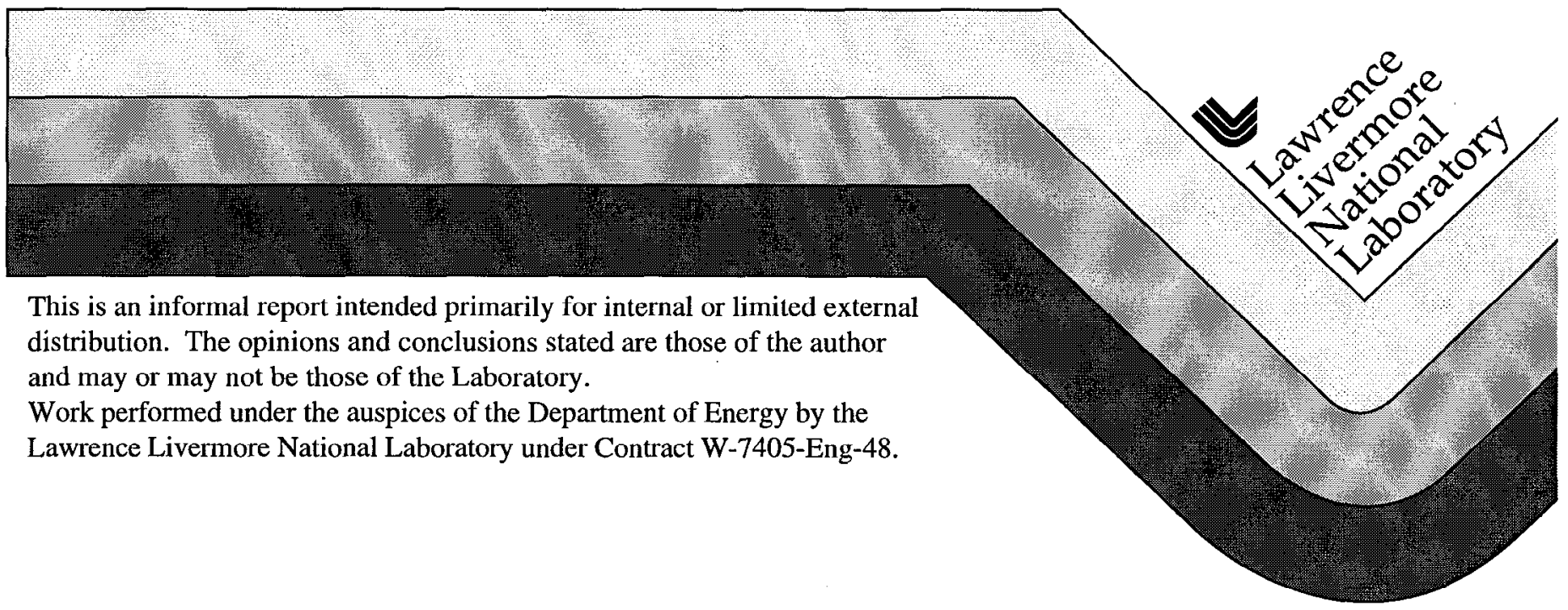




\section{DISCLAIMER}

This document was prepared as an account of work sponsored by an agency of the United States Government. Neither the United States Government nor the University of California nor any of their employees, makes any warranty, express or implied, or assumes any legal liability or responsibility for the accuracy, completeness, or usefulness of any information, apparatus, product, or process disclosed, or represents that its use would not infringe privately owned rights. Reference herein to any specific commercial product, process, or service by trade name, trademark, manufacturer, or otherwise, does not necessarily constitute or imply its endorsement, recommendation, or favoring by the United States Government or the University of California. The views and opinions of authors expressed herein do not necessarily state or reflect those of the United States Government or the University of California, and shall not be used for advertising or product endorsement purposes.

This report has been reproduced directly from the best available copy.

Available to DOE and DOE contractors from the Office of Scientific and Technical Information

P.O. Box 62, Oak Ridge, TN 37831

Prices available from (615) 576-8401, FTS 626-8401

Available to the public from the

National Technical Information Service

U.S. Department of Commerce

5285 Port Royal Rd.

Springfield, VA 22161 


\section{Measuring Parameters of Large-Aperture Crystals used for Generating Optical Harmonics}

R. E. English, Jr., R. L. Hibbard, R. B. Michie, P. J. Wegner, J. M. Auerbach, M. A. Norton, M. D. Summers, and S.A. Perfect

Optical harmonic generation has long been known as a very effective means for extending the operating wavelength range of high-peak-power lasers. Generating optical harmonics in laser systems such as the National Ignition Facility (NIF), Inertial Fusion Energy (IFE) lasers such as Mercury, or lasers for isotope separation requires careful control of several parameters. Efficient transfer of power from the input beam to the harmonic beam requires the input and output waves to be phasematched; this is most often done by using the birefringence of a nonlinear optical crystal to cancel the effects of dispersion.

The purpose of this project was to develop tools for understanding the influence of crystal quality and crystal mounting on harmonic-generation efficiency at high irradiance. Measuring the homogeneity of crystals interferometrically, making detailed physics calculations of conversion efficiency, performing finiteelement modeling of mounted crystals, and designing a new optical metrology tool were key elements in obtaining that understanding.

For this work, we used the following frequency-tripling scheme: type I secondharmonic generation followed by type II sum-frequency mixing of the residual fundamental and the second harmonic light. The doubler was potassium dihydrogen phosphate (KDP), and the tripler was deuterated KDP (KD*P). With this scheme, near-infrared light $(1053 \mathrm{~nm})$ can be frequency tripled (to $351 \mathrm{~nm}$ ) at high efficiency (theoretically $>90 \%$ ) for high irradiance $\left(>3 \mathrm{GW} / \mathrm{cm}^{2}\right)$.

Spatial variations in the birefringence of the large crystals studied here (37 to $41 \mathrm{~cm}$ square by about $1 \mathrm{~cm}$ thick) imply that the ideal phase-matching orientation of the crystal with respect to the incident laser beam varies across the crystal. We have shown that phase-measuring interferometry can be used to measure these spatial variations. We observed transmitted wavefront differences between orthogonally polarized interferograms of $\lambda / 50$ to $\lambda / 100$, which correspond to index variations of order $10^{-6}$. On some plates that we measured, the standard deviation of angular errors is 22-23 $\mathrm{rrad}$ (see Fig. 1); this corresponds to a $1 \%$ reduction in efficiency.

Because these conversion crystals are relatively thin, their surfaces are not flat (deviate by $\pm 2.5 \mu \mathrm{m}$ from flat). A crystal is mounted against a precision-machined surface that supports the crystal on four edges. This mounting surface is not flat either (deviates by $\pm 2.5 \mu \mathrm{m}$ from flat). A retaining flange presses a compliant element against the crystal. The load thus applied near the edges of the crystal surface holds it in place. See Fig. 2. We performed detailed finite-element modeling to predict the resulting shape of the mounted crystal. The prediction agreed with measurements of mounted crystals. 


\section{Distributions}

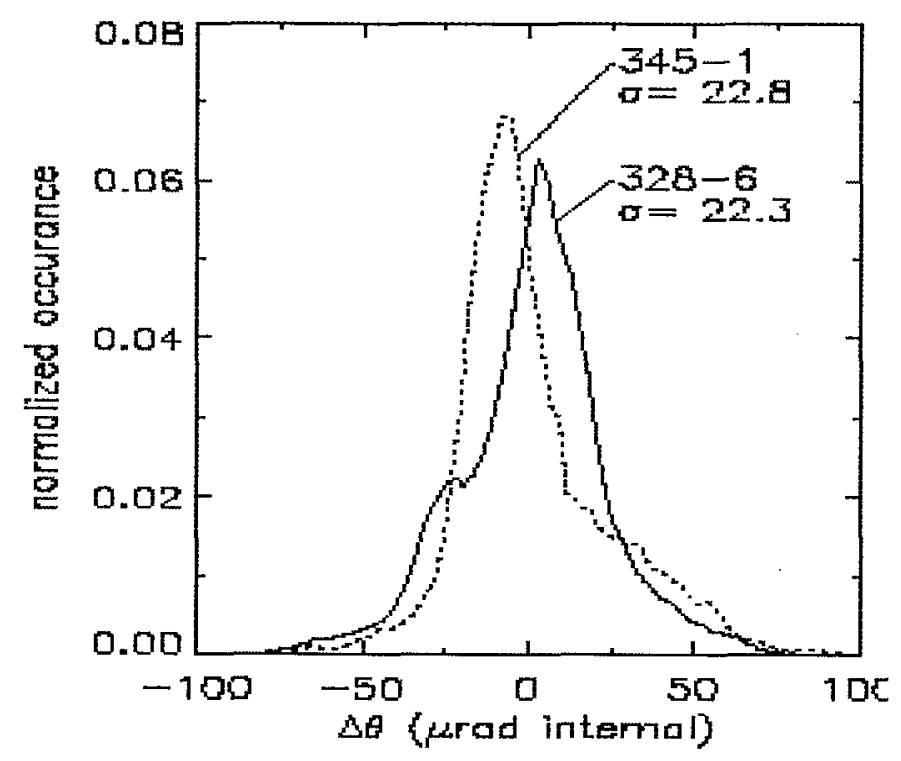

Fig. 1. A histogram of the angular errors in crystals, estimated from orthogonally polarized interferograms, is shown above. Two crystal are shown (designated 345-1 and 328-6). The histogram is number of occurrences in the interferogram file vs. angular error. The standard deviation of the distributions is $22-23 \mu \mathrm{rad}$.
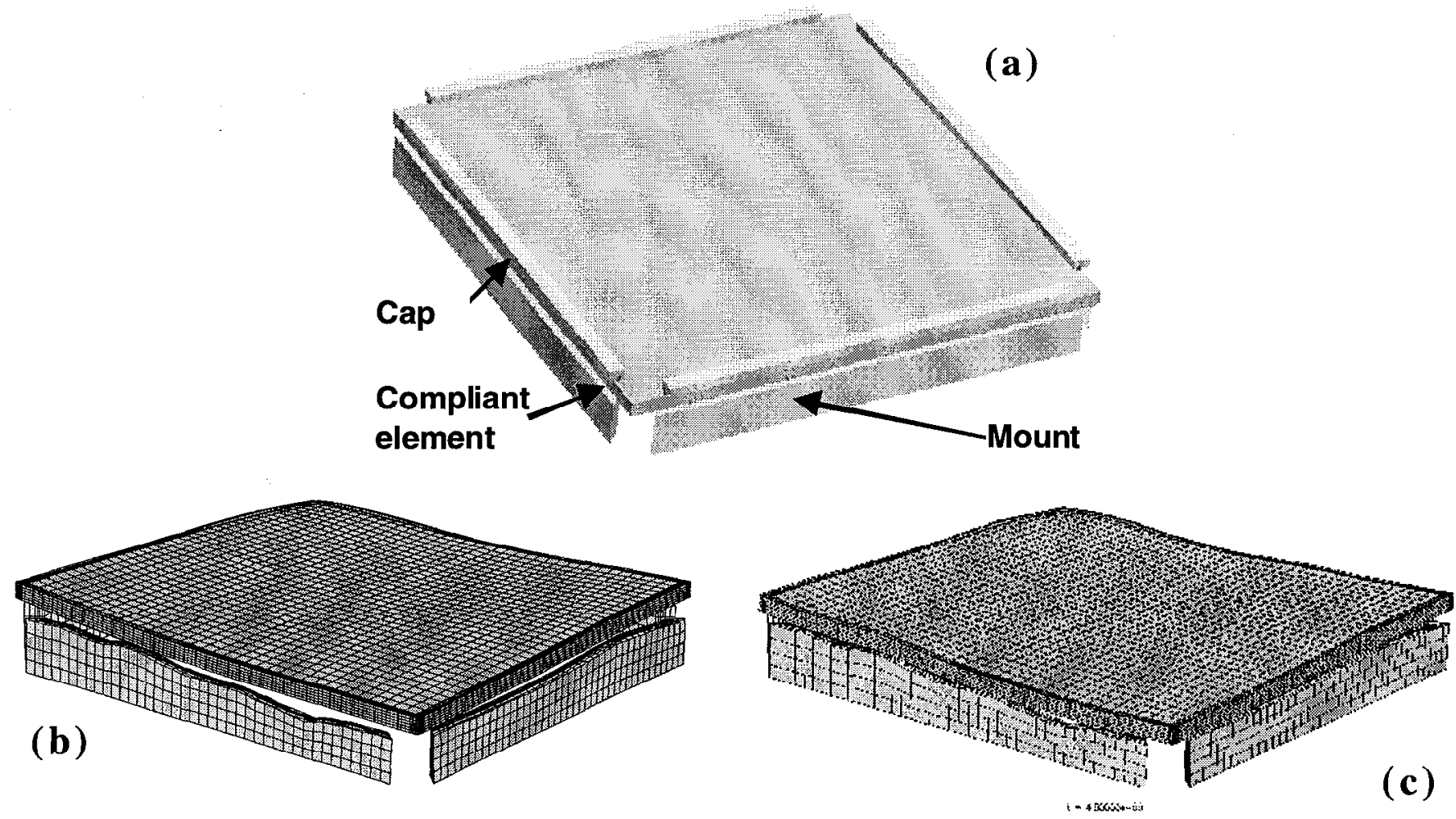

Fig. 2. The retaining flange (or cap) presses a compliant element against the crystal mount (a). The nonflat crystal is shown in a non-flat mount before applying the load (b). Finite element analysis was used to accurately predict the resulting shape of the mounted crystal after the load was applied (c). 
We computed the physics of the frequency-conversion process to better quantify the effects on efficiency of variation in the crystal's axis, changes in the shape of the crystal, and mounting-induced stress. We were able to accurately predict the frequency-conversion performance of $37-\mathrm{cm}$ square crystals on Beamlet, a one-beam scientific prototype of the NIF laser architecture, using interferometric measurements of the mounted crystals and the model. In a $2 \omega$ measurement campaign, the model predicted $64.9 \%$ conversion efficiency; $64.1 \%$ was observed. When detuned by $640 \mu \mathrm{rad}$, the model and measurement agreement is even better (both were $10.4 \%$ ). See Fig. 3.

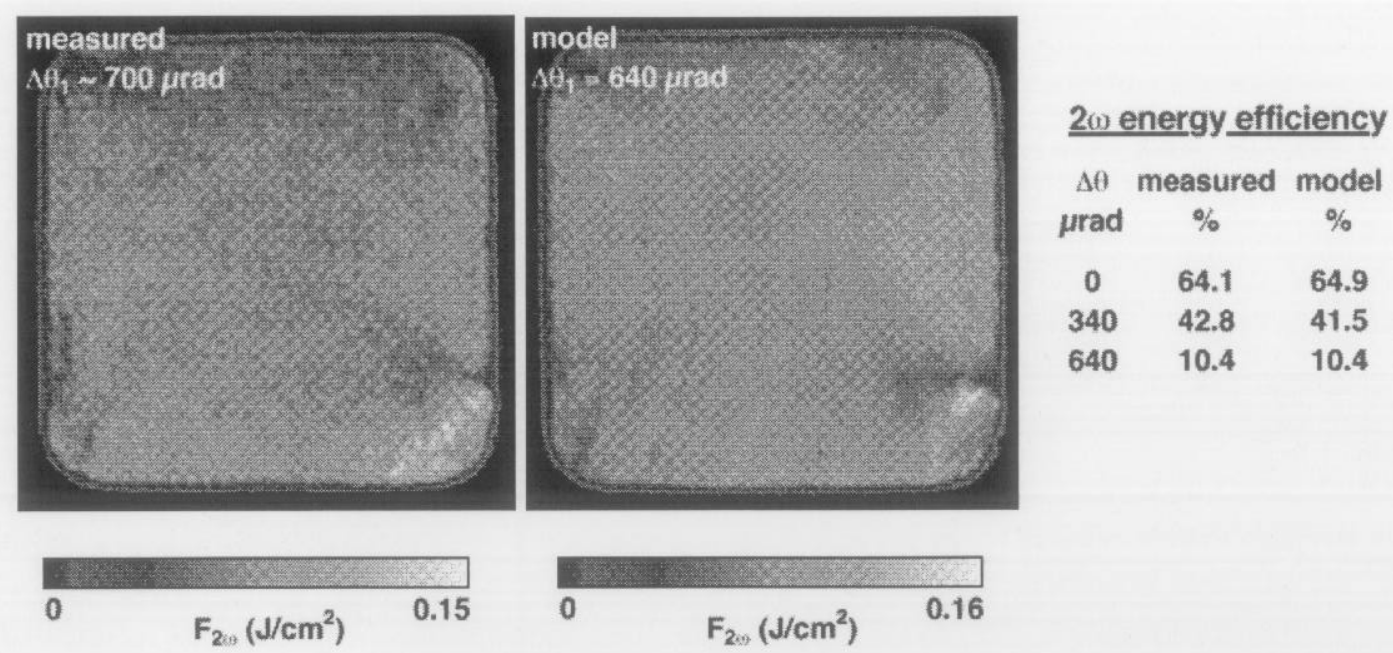

Fig. 3. Shown above left (labeled measured) is a near-field measurement of the $2 \omega$ irradiance for a laser shot detuned $700 \mu \mathrm{rad}$ from ideal phase matching. The predicted near-field (labeled as model) was computed from interferometric measurements of mounted crystals, then detuned $640 \mu \mathrm{rad}$. The comparison between the two is quite favorable. The table at right of the figure compares the observed energy efficiency with the predicted values.

Finally, we completed the design and initial testing of a new optical metrology tool to measure the spatial variation of frequency conversion. This system employs a high-power subaperture beam from a commercial laser oscillator and rod amplifier. The beam interrogates the crystal's aperture by moving the crystal horizontally on a translation stage and translating the laser beam vertically on an optical periscope. Precision alignment is maintained by means of a full-aperture reference mirror, a precision-machined surface on the crystal mount, and autocollimators (the goal for angular errors is $10 \mu \mathrm{rad}$ ). The autocollimators track the mounting angle of the crystal and the direction of the laser beam with respect to the reference mirror. The conversion efficiency can be directly measured by recording $1 \omega, 2 \omega, 3 \omega$ energy levels during the scan and by rocking (i.e., tilting) the crystal mount over an angular range. A photograph of the hardware is shown in Fig. 4. 


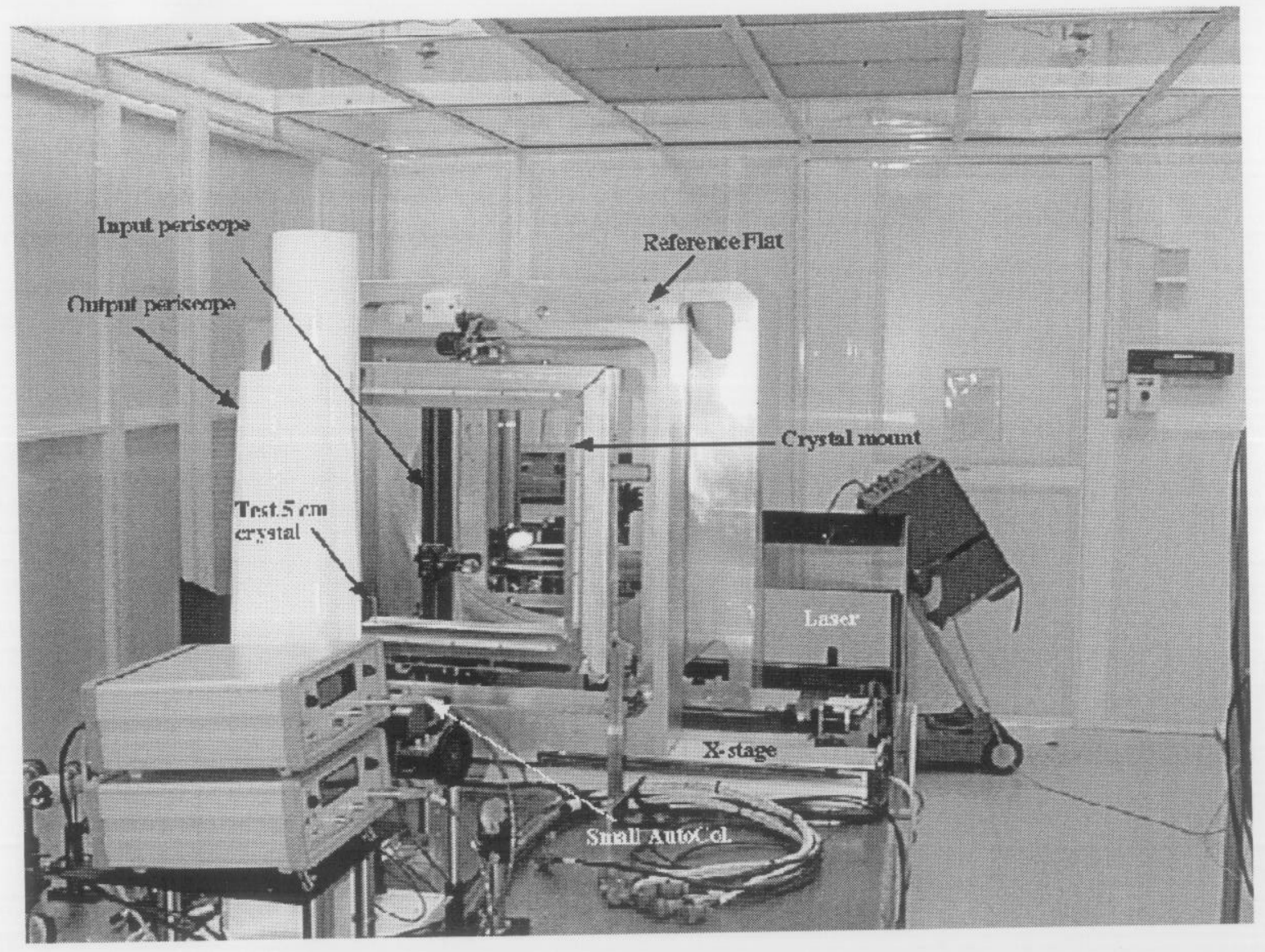

Fig. 4. A high-power subaperture beam from a commercial laser is used to measure the local frequency conversion efficiency. The crystal mount can be translated horizontally; the laser beam can be translated vertically. Autocollimators monitor the angle of incidence of the laser beam an the crystal during a scan. This angle control combined with energy measurement provides for accurate measurement of the phase matching angle.

\section{Publications}

Hibbard, R.L., R.B. Michie, M.D. Summers, L.W. Liou, “Development of a metrology instrument for mapping the crystallographic axis in large optics," 1998 OSA Technical Digest Series, Optical Fabrication and Testing, 12, 71, UCRL-MI-131111.

Hibbard, R.L., R. E. English Jr., J.J. DeYoreo, R.C. Montesanti, “Frequency converter design and manufacturing considerations for the National Ignition Facility," 1998 OSA Technical Digest Series, Optical Fabrication and Testing, 12, 74, UCRL-MI-131110. 